\title{
Importance of mangrove shorelines for rainbow parrotfish Scarus guacamaia: habitat suitability modeling in a subtropical bay
}

\author{
Ethan G. P. Machemer ${ }^{1}$, John F. Walter III $^{2}$, Joseph E. Serafy ${ }^{2,3}$, \\ David W. Kerstetter ${ }^{1, *}$ \\ ${ }^{1}$ Nova Southeastern University Oceanographic Center, 8000 North Ocean Drive, Dania Beach, Florida 33004, USA \\ ${ }^{2}$ NOAA-NMFS Southeast Fisheries Science Center, 75 Virginia Beach Drive, Miami, Florida 33149, USA \\ ${ }^{3}$ University of Miami, Rosenstiel School of Marine and Atmospheric Science, 4600 Rickenbacker Causeway, Miami, \\ Florida 33149, USA
}

\begin{abstract}
Rainbow parrotfish Scarus guacamaia is a coral-reef herbivore that requires both mangrove and coral-reef habitat to complete its life cycle. This species is listed as 'vulnerable' by the International Union for Conservation of Nature. The present study used a long-term visual survey of mangrove fishes to develop a predictive habitat model for juvenile $S$. guacamaia. The factors tested were temperature, dissolved oxygen, salinity, average depth, distance from offshore channel openings, temperature variation $(\Delta T)$, and salinity variation $(\Delta S)$. The average depth, distance from offshore channel openings, $\Delta T$, and $\Delta S$ emerged as significant within the model evaluations. The results suggested that high variation in salinity reduces mangrove habitat suitability for this species. Salinity variation along many of south Florida's coastal bays is largely driven by water management-related freshwater canal discharges. Everglades restoration efforts seek to reduce $\Delta S$ along south Florida's mainland shoreline; thus, if successful, restoration may also confer benefits to Scarus guacamaia through the subsequent expansion of suitable mangrove habitat.
\end{abstract}

KEY WORDS: Conservation $\cdot$ Logistic regression $\cdot$ Habitat suitability $\cdot$ Coral reefs $\cdot$ Ontogenetic shifts

\section{INTRODUCTION}

Rainbow parrotfish Scarus guacamaia is the largest herbivorous fish in the Atlantic Ocean and Caribbean Sea and is the only scarid that possesses an obligate, functional dependence on mangroves for juvenile habitat (Dorenbosch et al. 2006, Mumby 2006, Nagelkerken 2007). Rainbow parrotfish are listed as 'vulnerable' under International Union for the Conservation of Nature (IUCN) criteria (Ferreira et al. 2008), due to a reduction in suitable habitat and the reduced size of individuals due to fishing pressure. With the listing of 2 acroporid corals Acropora palmata and A. cervicornis as threatened under the En- dangered Species Act (National Marine Fisheries Service 2006), there is concern that declines in rainbow parrotfish populations will link to reductions in algal grazing and therefore further accelerate coral declines (National Marine Fisheries Service 2011).

Mumby \& Hastings (2008) suggested that parrotfishes, and specifically Scarus guacamaia, might enhance coral recovery through grazing on macroalgae (see also McClanahan et al. 2002). S. guacamaia feed mainly by scraping epiphytic macroalgae from coral structures (Bellwood et al. 2004), and high levels of parrotfish grazing have been shown to lead to a 2 -fold increase in the recruitment of corals, such as Porites spp. and Agaricia spp. in the Bahamas (Mum- 
by \& Hastings 2008). Although the linkages between rainbow parrotfish and healthy coral reefs are complex, the indications that rainbow parrotfish may improve reef health give impetus for defining critical factors in rainbow parrotfish life history.

Scarus guacamaia exhibit an ontogenetic habitat shift: juveniles reside along mangrove-lined shorelines before moving to coral reefs as they mature (Dorenbosch et al. 2006). The biomass of rainbow parrotfish more than doubles when coral reefs are located adjacent to rich mangrove resources, defined as coverage of fringing red mangrove Rhizophora mangle of $\geq 35 \%$ within a region (Mumby 2006). This functional dependency appears reinforced by evidence that local population extinctions of $S$. guacamaia in the Belize barrier reef system corresponded with the removal of mangrove stands (Mumby et al. 2004). The South Florida ecosystem once supported substantial mangrove habitats, but with increasing human population density, habitat alteration, and water regime changes, the mangrove coverage in the region has declined by $80 \%$ (Snedaker \& Biber 1996). In addition, due to the long-term anthropogenic disturbance of this ecosystem, optimal habitats defined within the Biscayne Bay region may no longer represent true ecological baselines. Although substantial mangrove habitat remains $-1500 \mathrm{~km}^{2}$ within the Everglades (Olmsted \& Loope 1984), including an estimated measurement of $125 \mathrm{~km}^{2}$ within the Biscayne Bay study area alone - only a few areas appear to support juvenile rainbow parrotfish (Serafy et al. 2003). Thus, it is likely that it is not solely the presence of mangroves but rather a suite of other abiotic or biotic factors that define habitat suitability for $S$. guacamaia. These factors may include salinity, temperature, dissolved oxygen, average depth, and distance from offshore channel openings that present physiological and physical constraints on the life history of this species.

In the present study, we develop a logistic regression model to predict the presence and absence of rainbow parrotfish in mangrove habitats of southern Biscayne Bay, South Florida, USA, with the goal of better defining the characteristics that make a given mangrove habitat suitable for juvenile rainbow parrotfish. Biscayne Bay's watershed, from north to south, grades from urban to suburban to agricultural and finally serves primarily as parkland. We use data collected from a long-term ( $>10 \mathrm{yr}$ ) visual survey of mangrove fishes from southern Biscayne Bay. To the extent that presence-absence defines habitat suitability, logistic regression is a valuable tool for determining the factors that harbor or exclude animals from habitats (e.g. Sampson \& Al-Jufaily 1999, Fransen et al. 2006, Bi et al. 2007). Predictive habitat modeling also allows the assessment of the geographic distribution of a species to visualize patterns across, and affecting, their range and to elucidate factors that may influence their life history that are not readily quantified through other methods.

South Florida water management regime changes have substantially altered the habitat for Scarus guacamaia in southern Biscayne Bay by either diverting more water through canals (as opposed to groundwater) or by altering the volume and frequency of freshwater releases, creating drastic fluctuations in salinity and nutrient loads (Serafy et al. 2007). Therefore, it is critical to define the current juvenile habitat prior to further anthropogenic changes to this ecosystem. Furthermore, because $S$. guacamaia may provide an important ecosystem service for threatened corals on the Florida reef tract, defining juvenile habitat for the species may be an important accessory step in the protection of coral resources.

\section{MATERIALS AND METHODS}

\section{Study region}

The focal lagoon system comprised southern Biscayne Bay from Key Biscayne to Barnes Sound (Fig. 1). Northern Biscayne Bay's watershed is heavily developed, and its once-mangrove-lined shorelines have mostly been replaced by seawalls and rip-rap (limestone boulders). Estuarine-like characteristics occur only near points of freshwater inflow during the wet and early dry season (Wang et al. 2003). Southern Biscayne Bay generally averages $<3 \mathrm{~m}$ in depth, with few deeper areas, and mainly small cuts and inlets to the ocean. This lagoon system leads to highly spatiotemporally variable salinity regimes due to limited tidal flushing and high freshwater input through canals with gated control structures. The greatest salinity fluctuations occur near anthropogenic canal mouths along the western margin of southern Biscayne Bay, while the smallest fluctuations occur near the inlets and passes (Wang et al. 2003), which are buffered by connections to the ocean.

Southern Biscayne Bay is predominantly lined by red mangroves on both the mainland and the leeward sides of the keys that define the bay's eastern border (Serafy et al. 2003), and mangroves are also the dominant shoreline habitat type of the region. Red mangrove stands occur in narrow bands transitioning to black mangrove Avicennia germinans and 


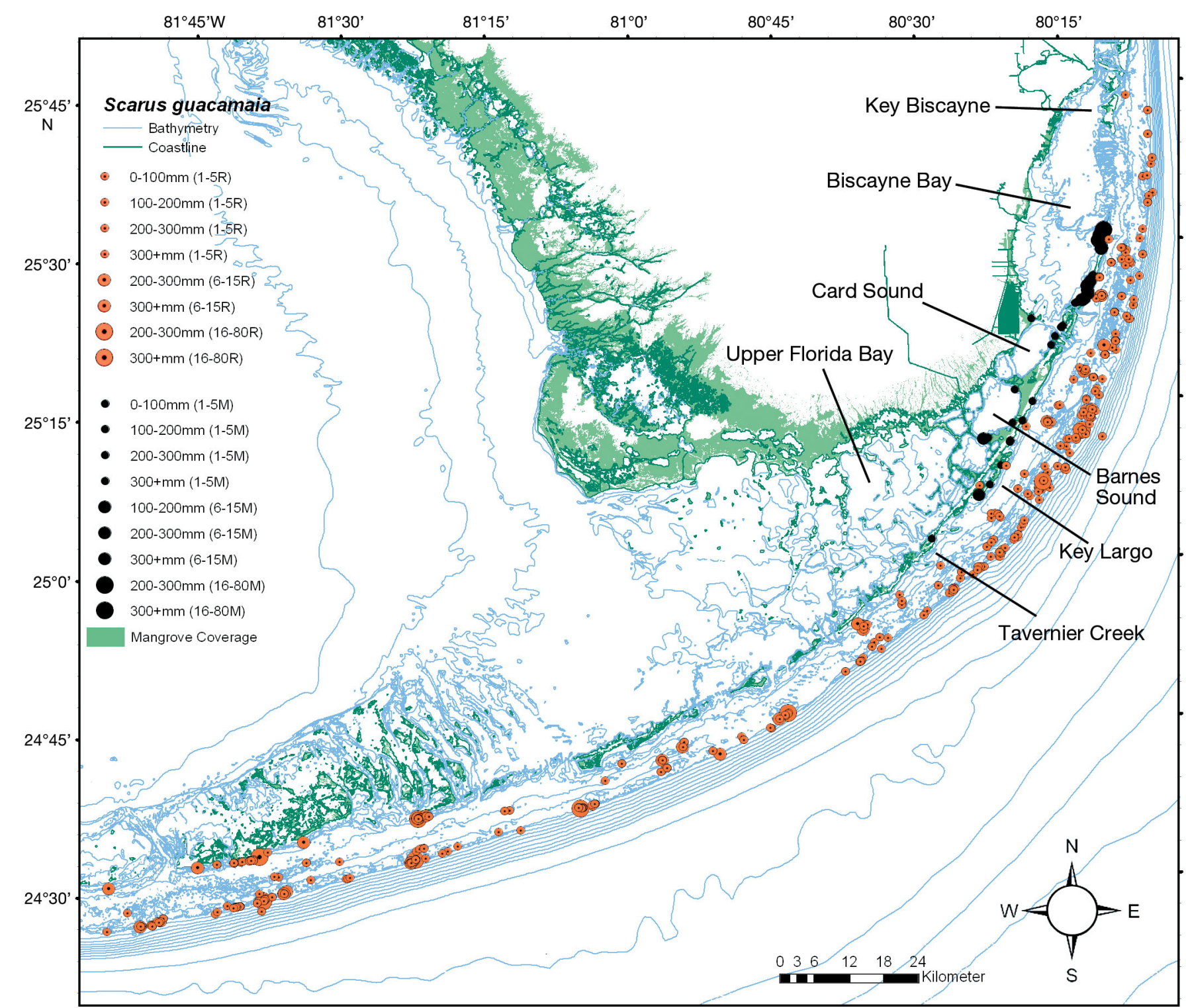

Fig. 1. Scarus guacamaia. Location and size of observed rainbow parrotfish individuals based on Mangrove Visual Survey (M, black circles, 1998-2007) and Reef Visual Census (R, red circles, 1979-2005) data. Legend in figure gives fish size (in mm), number of individuals seen (in parentheses), and survey ( $\mathrm{M}$ or $\mathrm{R}$ )

then white mangrove Laguncularia racemosa with increasing distance from the shoreline. Scarus guacamaia occurs in low abundance in the Biscayne Bay region, in comparison to other more prevalent teleost families, such as Haemulidae and Lutjanidae, but this species is more abundant here than in other parts of the Caribbean Sea (Ferreira et al. 2008).

\section{Mangrove visual survey}

The data examined in the present study were part of a long-term (1998 to 2009) fish survey known as the Mangrove Visual Survey (MVS) (see full description in Serafy et al. 2003). Data from 1998 to 2007 were used as the 'training' data to develop the model, and data from 2008 to 2009 were used to test the resulting model. The spatial extent of the MVS is shown in Fig. 1. This survey entailed snorkeling a $30 \times 2 \mathrm{~m}\left(60 \mathrm{~m}^{2}\right)$ transect parallel to the shore and recording the identity, number, and size of the fishes observed. Each transect-specific predictor variable represents an independent field measurement of each of the abiotic parameters. The water temperature, salinity, and dissolved oxygen were measured at each transect using a Hydrolab ${ }^{\circledR}$ multi-probe 
instrument. Depth was measured along each transect at intervals of $15 \mathrm{~m}$ using a $2 \mathrm{~m}$ long polyvinyl chloride (PVC) pole marked at $2 \mathrm{~cm}$ intervals (Serafy et al. 2003). The average depth of the surveyed sites ranged from $9 \mathrm{~cm}$ to $175 \mathrm{~cm}$. The transect locations were chosen from mangrove shorelines according to a stratified random sampling design with sampling taking place from 09:00 h to 17:00 h local time to minimize potential visual identification problems associated with low light conditions. The sampling took place during consecutive wet and dry seasons (i.e. typically July to September and January to March, respectively). Data from 1812 transect sites were used, with 15 sites omitted due to a lack of complete contemporaneous water temperature, salinity, and dissolved oxygen measurements. Data from the 2 most recent years available (2008 and 2009) were omitted for the model development and instead reserved for model validation. The numbers and lengths of Scarus guacamaia obtained from a separate visual survey conducted on coral reefs (the Reef Visual Census) (see Bohnsack \& Bannerot 1986) were used for visual display purposes of ontogenetic shifts in habitat use but were not used in the regression modeling due to a lack of complete contemporaneous abiotic factor measurements.

\section{Logistic regression modeling and analysis}

Logistic regression is a common approach to habitat modeling to identify variables that might define the optimal or preferred habitat of a species (e.g. Freckleton et al. 2006). The model predicts the probability that an event will occur as a linear function of one or more independent variables. A linear function is appropriate because the data fall within a similar range of values, and transformation of the data to a logarithmic scale is not necessary.

The logistic regression model initially tested the following 7 parameters: temperature $\left({ }^{\circ} \mathrm{C}\right)$, dissolved oxygen $\left(\mathrm{mg} \mathrm{l}^{-1}\right)$, salinity (parts per thousand, \%) average depth $(\mathrm{cm})$, distance from offshore channel opening $(\mathrm{km})$, temperature variation $(\Delta T)$, and salinity variation $(\Delta S)$. The values for $\Delta T$ and $\Delta S$ were calculated by taking all of the measurements of these variables within binned sites within a $0.5 \mathrm{~km}$ radius and then calculating the standard deviation of these binned sites against the range of measurements across all sites. Another 18 sites were omitted due to $\Delta T$ and $\Delta S$ values of 0 that resulted for single, spatially isolated sites. Distances from offshore channel openings were derived from GIS map coverage and estimated by tak- ing the GPS-based location in the center of each of 8 channels within the study area and measuring the straight-line distance to each site. The average depth value was determined for each site during surveying as the average depth along the MVS transect adjacent to the mangrove shoreline. Each transect was treated as the response unit of independent replication, with a minimum distance of $50 \mathrm{~m}$ separating each transect and with each abiotic parameter quantified at a spatial resolution of $50 \mathrm{~m}$. Spatial autocorrelation was calculated for each parameter across the entire data set using Geary's $C$ test, each test of which returned a Geary's $C$ value of 1 , indicating that there was no spatial autocorrelation within the data. Collinearity was calculated between the parameters prior to the analysis, and the variance inflation factor (VIF) between parameters was never $>5$, the highest being between average depth and $\Delta S$ with a value of 2.127 , indicating that multicollinearity was not a concern.

The logistic regression model was fit using a backward stepwise method with least-squares estimation. The final variable selection was based on Akaike information criterion (AIC) values (Burnham \& Anderson 2002). The corresponding predicted regression values were then plotted spatially using ArcGIS (ESRI, version 9.2).

Model performance was evaluated by using MVS data from years 2008 and 2009 to compare model predictions against observed presence/absence at sites with data. Values for the significant factors were input into the derived equation from the training data to calculate a predicted regression value for each site. True positives were determined as sites with presence where the predicted probability of presence was $>0.2$, and true negatives were determined as sites with absence where the predicted probability value was $<0.2$. The threshold of 0.2 was chosen because using the default threshold of 0.5 works poorly when mapping species with low prevalence by underestimating true positives and producing many false negatives (Freeman \& Moisen 2008). Setting the threshold at 0.2 provides greater confidence that the locations where the species is termed as present actually have the species. Specifically, the model was evaluated for both sensitivity, the proportion of true positives correctly identified, and specificity, the proportion of true negatives correctly identified.

\section{RESULTS}

In the MVS dataset used for the training data, rainbow parrotfish were observed at 106 of the 1779 sites 
(6\% positive), with a total of 551 individuals (Fig. 1). Of these individuals, 186 were of mature size (size at first maturity, L50) based on total length (TL) $>35 \mathrm{~cm}$ (Fig. 2) (Winn \& Bardach 1960). The remaining individuals ranged in length from 3 to $33 \mathrm{~cm}$ and represented primarily age 0 and 1 yr fish based upon presumed growth rates of 0.5 to $1.0 \mathrm{~cm}$ per week (Bortone et al. 1992, Paddack et al. 2009). Fig. 1 also shows adult fish on coral reefs to indicate both adult and juvenile habitats. Length frequency histograms for fish observed in mangroves (MVS) versus those on adjacent reefs (RVC) show the clear ontogenetic separation between the 2 habitats (Fig. 2).

Temperatures varied from 18.8 to $33.1^{\circ} \mathrm{C}$ across the sites with rainbow parrotfish presence, a narrower range than the temperature range of 12.5 to $36.2^{\circ} \mathrm{C}$ across all of the study sites. In addition, only 15 of the 106 sites with rainbow parrotfish presence based on the MVS data had temperatures below $22^{\circ} \mathrm{C}$. Dissolved oxygen varied from 0.65 to $16.97 \mathrm{mg} \mathrm{l}^{-1}$ across all sites and from 2.4 to $14.07 \mathrm{mg} \mathrm{l}^{-1}$ across sites with rainbow parrotfish. Salinity varied from 0.37 to $42.4 \%$ across all sites but only varied from 23.74 to $39.1 \%$ across sites where the studied fish occurred.
The average depth varied from 9 to $175 \mathrm{~cm}$ across all of the sites and varied from 45.67 to $151.8 \mathrm{~cm}$ across the occupied sites. The distances from offshore channel openings varied from 0.12 to $45.64 \mathrm{~km}$ across all of the study sites, while that at occupied sites varied between 0.19 and $10.17 \mathrm{~km} . \Delta T$ varied from 0.09 to 9.35 across all sites and from 0.12 to 5.84 across the sites with parrotfish present. $\Delta S$ varied from 0.1 to 14.13 across all sites but only varied from 0.3 to 4.7 across sites occupied by rainbow parrotfish.

In the stepwise regression analysis, the full model started with 7 factors: temperature, dissolved oxygen, salinity, average depth, distance from offshore channel opening, $\Delta T$, and $\Delta S$ (Table 1). Four significant factors were retained in the final model: average depth, distance from offshore channel opening, $\Delta T$, and $\Delta S$ (Table 2, Fig. 3):

where

$$
\text { Predicted presence }=1 /\left(1+\mathrm{e}^{-z}\right)
$$

$$
z=-4.23+\left(0.034 x_{1}\right)+\left(-0.29 x_{2}\right)+\left(0.53 x_{3}\right)+\left(-0.81 x_{4}\right)
$$

in which $x_{1}$ is the average depth value, $x_{2}$ is the distance from offshore channel opening, $x_{3}$ is DT, and $x_{4}$ is DS.

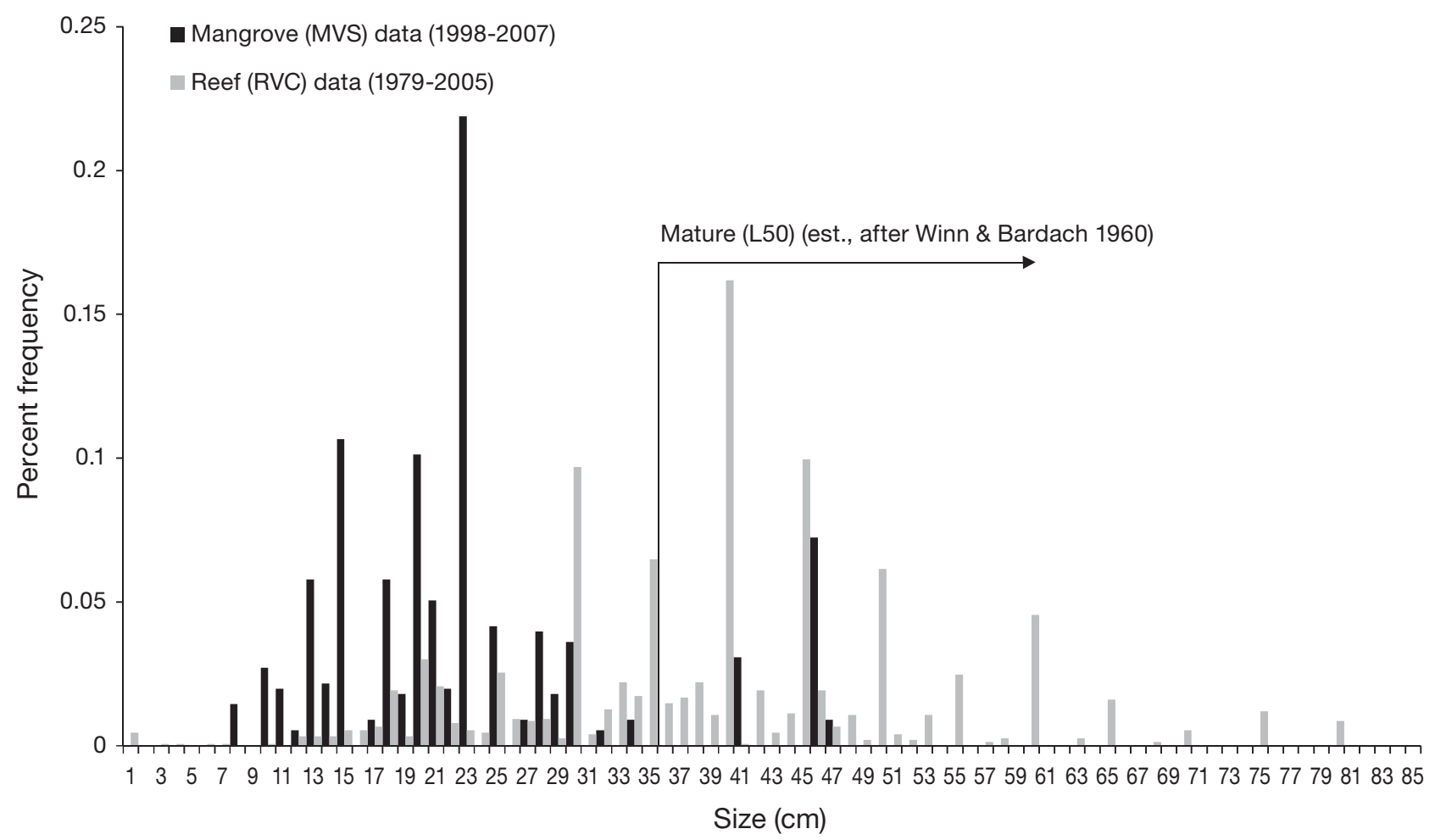

Fig. 2. Scarus guacamaia size distribution showing ontogenetic habitat shift from individuals observed in mangroves (MVS, black bars) to those on coral reefs (RVC, gray bars). MVS refers to the Mangrove Visual Survey (see Serafy et al. 2003), which used a 'belt-transect' method to estimate identity, number, and size-structure of fishes observed. RVC refers to the Reef Visual Census (see Bohnsack \& Bannerot 1986), which used a stationary plot technique to count the number and length of fish observed in a visually estimated cylinder 
Table 1. Akaike information criterion (AIC) values from each step of logistic regression model with significant factors and corresponding individual values

\begin{tabular}{|c|c|c|c|}
\hline Factor & df & Deviance & AIC \\
\hline AIC - 490.35 & & & \\
\hline Salinity & 1 & 474.41 & 488.41 \\
\hline Dissolved oxygen & 1 & 474.6 & 488.6 \\
\hline Temperature & 1 & 475.39 & 489.39 \\
\hline None & 0 & 474.35 & 490.35 \\
\hline$\Delta T$ & 1 & 494.51 & 508.51 \\
\hline Distance from channel opening & 1 & 504.73 & 518.73 \\
\hline$\Delta S$ & 1 & 510.17 & 524.17 \\
\hline Average depth & 1 & 522.9 & 536.9 \\
\hline Step $1 \quad$ AIC -488.41 & & & \\
\hline Dissolved oxygen & 1 & 474.65 & 486.65 \\
\hline Temperature & 1 & 474.45 & 487.45 \\
\hline None & 0 & 474.41 & 488.41 \\
\hline$\Delta T$ & 1 & 495.89 & 507.89 \\
\hline Distance from channel opening & 1 & 509.69 & 521.69 \\
\hline$\Delta S$ & 1 & 519.85 & 531.85 \\
\hline Average depth & 1 & 522.9 & 534.9 \\
\hline $\mathrm{AIC}-486.65$ & & & \\
\hline Temperature & 1 & 476.32 & 486.32 \\
\hline None & 0 & 474.65 & 486.65 \\
\hline$\Delta T$ & 1 & 495.93 & 505.93 \\
\hline Distance from channel opening & 1 & 510.23 & 520.23 \\
\hline$\Delta S$ & 1 & 520.48 & 530.48 \\
\hline Average depth & 1 & 526.12 & 536.12 \\
\hline Step 3 (Final) $\quad$ AIC - 486.32 & & & \\
\hline None & 0 & 476.32 & 486.32 \\
\hline$\Delta T$ & 1 & 496.32 & 504.34 \\
\hline Distance from channel opening & 1 & 512.25 & 520.25 \\
\hline$\Delta S$ & 1 & 521.23 & 529.23 \\
\hline Average depth & 1 & 527.87 & 535.87 \\
\hline
\end{tabular}

Table 2. Scarus guacamaia. Regression output values and summary statistics from final logistic regression model predicting rainbow parrotfish presence and absence in the South Florida mangrove-coral reef ecosystem based on environmental variables

\begin{tabular}{|lrcrr|}
\hline & Coefficient & $\begin{array}{c}\text { Standard } \\
\text { error }\end{array}$ & $Z$-value & $\operatorname{Pr}(>|Z|)$ \\
\hline & -4.227186 & 0.708909 & -5.963 & $<0.0001$ \\
(Intercept) & 0.034351 & 0.005086 & 6.754 & $<0.0001$ \\
Average depth & -0.289407 & 0.060882 & -4.754 & $<0.0001$ \\
Dist. from channel opening & 0.535723 & 0.131599 & 4.071 & $<0.0001$ \\
$\Delta T$ & -0.811179 & 0.176808 & -4.588 & $<0.0001$ \\
$\Delta S$ & & 803.47 & $\mathrm{df}=1778$ \\
\hline Null deviance & 476.32 & $\mathrm{df}=1774$ \\
Residual deviance & 486.32 & & \\
Akaike information criterion & \multicolumn{2}{c}{. } \\
\hline
\end{tabular}

\section{Model diagnostics}

In the final model, several variables had significant correlations (Table 3). The only correlation that was not significant at the $\mathrm{p}<0.05$ level was that between the distance from the offshore channel opening and the $\Delta T$ value $(\mathrm{p}<0.053)$. The correlations between average depth, distance from offshore channel opening, and $\Delta T$ were low, demonstrating a greater level of independence between these variables. There were, however, stronger correlations between the $\Delta S$ value and the other 3 variables with r-values of $-0.191(p<0.001)$ for average depth, $0.112(p<0.001)$ for $\Delta T$, and 0.39 for the distance from the offshore channel opening.

\section{Model validation}

In the 2008-2009 MVS dataset used for the test data, rainbow parrotfish were observed at 53 of the 759 sites, for a total of 321 individuals. Model performance was tested on the sites where environmental data existed. The logistic regression model correctly predicted the presence or absence in $94.5 \%$ of the sites. This consisted of 36 true positive predictions and 681 true negative predictions versus 25 false positive predictions and 17 false negative predictions. These values give a specificity of 0.965 and a sensitivity of 0.679 .

\section{DISCUSSION}

Recent publications (e.g. Nagelkerken et al. 2000, Nagelkerken \& van der Velde 2002, Mumby et al. 2004, Dorenbosch et al. 2006) document the importance of mangrove habitats for Scarus guacamaia and, by proxy, the importance of mangroves for coral reefs because mangroves support herbivores that may improve coral resilience and recruitment (Mumby \& Hastings 2008). The presence of mangroves is likely important, but it is not a sufficient condition alone to support juvenile $S$. guacamaia; rather, there are various degrees of suitability of a given mangrove habitat. Our modeling work indicates that a combination of abiotic factors determine the probability of occurrence of juvenile $S$. guacamaia. 

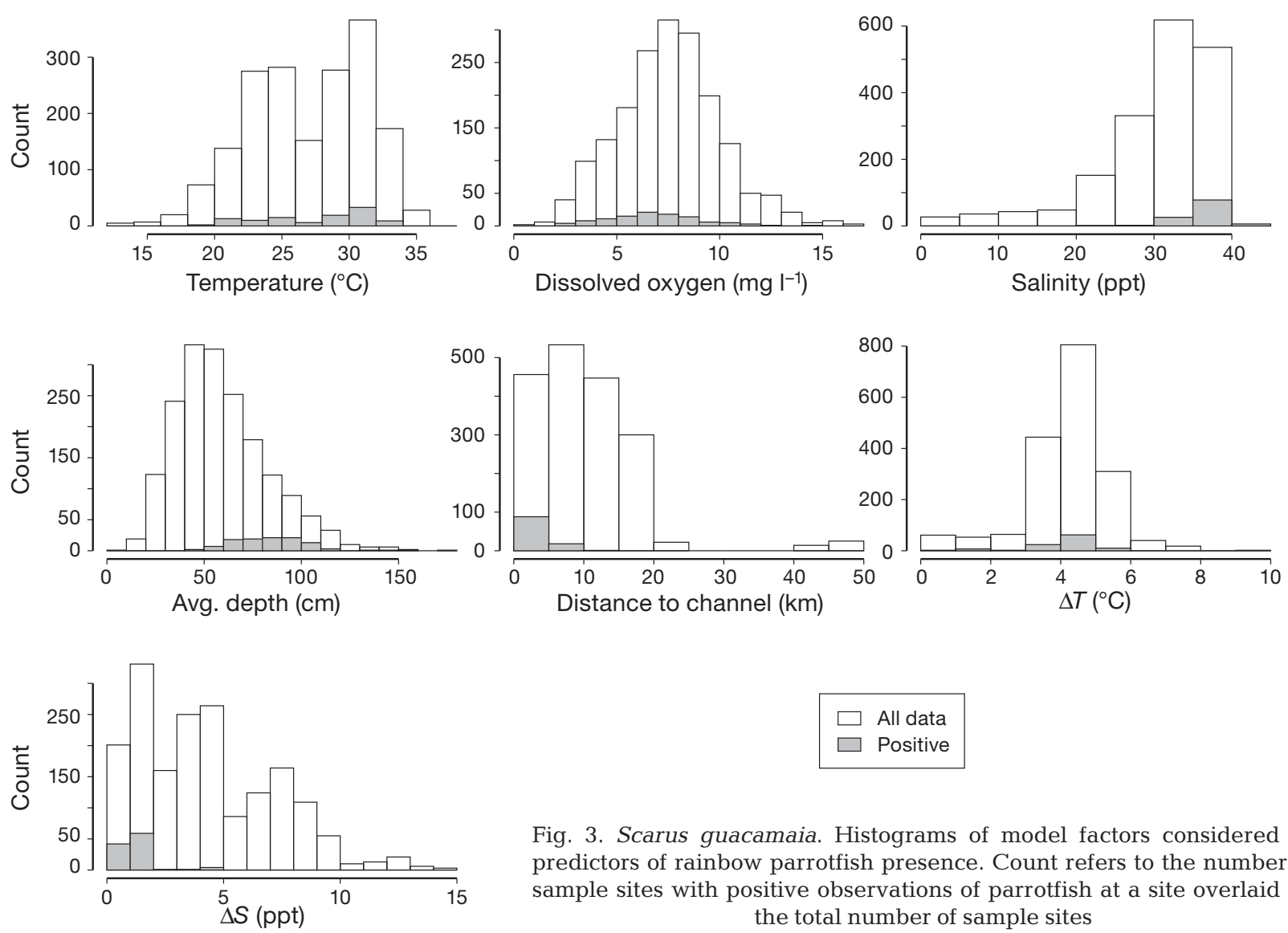

All data
Positive

Fig. 3. Scarus guacamaia. Histograms of model factors considered as predictors of rainbow parrotfish presence. Count refers to the number of sample sites with positive observations of parrotfish at a site overlaid on the total number of sample sites

Four habitat variables (average depth, distance from offshore channel opening, $\Delta T$, and $\Delta S$ ) were significant for predicting the presence of rainbow parrotfish. Some variables that should define the range of a species distribution (salinity and temperature) or the physiological limits to survival (dissolved oxygen) were not significant. In contrast, variables that described the dynamic nature of environmental conditions $(\Delta T$ and $\Delta S)$ were significant. While it is not surprising that these variables were significant, it was surprising that the abiotic factors of temperature and salinity were not, given the wide range of variability in the Biscayne Bay region that occurs with these factors from year to year via natural and anthropogenic influences.

The low temperature variability, which occurred within preferred physiological temperature conditions for parrotfish (Smith 2008), suggests that temperature alone was a poor predictor of rainbow parrotfish presence or absence in this region. However, although temperature was not significant in this model for Biscayne Bay, temperature clearly affects the wider biogeography of Scarus guacamaia and other scarids, which are almost all tropical or subtropical in distribution (Smith 1997). The $\Delta T$ value was significant with a positive coefficient, indicating

Table 3. Degrees of relationship between each pair of variables used in the logistic regression analysis with Pearson r-values. Paired relationship p-values are in parentheses. ${ }^{*} \mathrm{p}<0.001$

\begin{tabular}{|lcccc|}
\hline & Average depth & $\begin{array}{c}\text { Distance from offshore } \\
\text { channel opening }\end{array}$ & $\Delta T$ \\
\hline Average depth & - & $-0.0534(0.024)$ & $-0.0891^{*}$ & $-0.1912^{*}$ \\
Distance from offshore channel opening & $-0.0534(0.024)$ & - & $0.0458(0.053)$ & $0.3908^{*}$ \\
$\Delta T$ & $-0.0891^{*}$ & $0.0458(0.053)$ & $-0^{*}$ & $0.1124^{*}$ \\
$\Delta S$ & $-0.1912^{*}$ & $0.3908^{*}$ & $0.1124^{*}$ & - \\
\hline
\end{tabular}


that as the variability in temperature increased, the predicted presence of rainbow parrotfish also increased.

Within the study area, dissolved oxygen did not exhibit sufficient variability to be a limiting factor, and this narrow range likely led to its lack of influence in the regression model. Out of the 1779 sites in the MVS, only 8 sites with rainbow parrotfish had dissolved oxygen levels below $2 \mathrm{mg} \mathrm{l}^{-1}$, a limiting threshold and hypoxia constraint for many fishes (Chesney et al. 2000, Rummer et al. 2009). Dissolved oxygen is a highly transient factor affected by such factors as vegetative cover, algal bloom events, temperature, and tides (De Almeida e Silva et al. 2003), and changes in dissolved oxygen alone might be too transitory or ephemeral to drive the presence or absence of rainbow parrotfish. It is important to note that the MVS was conducted strictly during the day; low nocturnal dissolved oxygen levels may occur and may thus be a more important contributor to habitat suitability at night.

The distance from offshore channel openings was a significant model factor. In the full model, the distance from offshore channel openings and salinity exhibited high collinearity (39\%). However, model selection criteria based on AIC indicated that distance to offshore channel opening was a better predictor of presence/absence alone. Distance from these channel opening might play an important role across several life stages. Rainbow parrotfish spawn in oceanic areas, e.g. off Bermuda (Winn \& Bardach 1960), and larval settlement from the water column occurs inshore in mangrove habitats that function as nurseries. The fact that distance from offshore channel openings was selected may suggest that transport processes, which ultimately determine how rainbow parrotfish larvae enter the Biscayne Bay system, might play an important role in the apparent patterns of habitat utilization. It is possible that larval parrotfish will settle and develop into juveniles in a suitable mangrove habitat close in proximity to channel openings in the Keys to avoid added energetic costs associated with traveling farther to the mainland shoreline. Additionally, Dorenbosch et al. (2007) concluded that the migration of rainbow parrotfish adults from mangroves to coral reefs most likely takes place along island coastlines. The migration pathway to the Florida Reef Tract is shorter along shore from the Leeward Keys, while following shorelines from the mainland increases the distance traveled and the risk of predation (Fig. 1).

Salinity was not a significant predictor, largely due to the high correlation with the distance from off- shore channel openings; however, salinity is still an important factor structuring the population of Scarus guacamaia, which were only observed in the MVS dataset at salinities between 24 and $39 \%$. In contrast, variability in salinity $(\Delta S)$ was significant, indicating that more stable salinity regimes lead to a greater predicted presence of $S$. guacamaia. Many marine fishes are tolerant to gradual changes in salinity but experience increasing osmoregulatory costs with rapidly fluctuating salinities (Serrano et al. 2010). These increased costs of osmoregulation thereby indirectly restrict the number of species that can occupy highly variable salinity habitats, resulting in higher mean species richness values for reef fishes in sites with stable salinity (Serafy et al. 1997). Many reef fishes can endure short freshwater pulses but not constant exposure to the rapid salinity fluctuations that occur due to both natural and anthropogenic water releases in Biscayne Bay (Serafy et al. 1997). Salinity may be a more significant factor in a lagoon system with a large river discharge; however, in the relatively enclosed Biscayne Bay, salinity is not as significant for determining habitat presence. Pulsed freshwater releases through canal structures do mimic this discharge effect on a smaller scale, which may explain part of the significance of the modeled $\Delta S$ value.

The average depth was also significant, with a higher probability of occurrence in deeper water adjacent to the mangrove shoreline. Shallower waters may not support high levels of food resources, resulting in reduced utilization by Scarus guacamaia. Depths <1 m may be suboptimal for epiphytic plant and algal growth because air exposure and very high levels of surface solar radiation may cause photodamage to plant tissues (Häder et al. 1997). Deeper waters might also have more available space for swimming, foraging, and shelter as well as lessen the effects of predation by birds and other piscivores. Areas of greater water depth, combined with consistent tidal flushing, may also be less subject to changes in sediment loads, increasing the photic depth (Arthur \& Ball 1979).

The map of predicted regression values (Fig. 4) illustrates the spatial pattern of habitat utilization for juvenile Scarus guacamaia. Mangrove-lined shorelines along the leeward side of the keys of Biscayne Bay and northern Card Sound have the highest predicted regression values. Mangrove coverage is higher in these locations than others within the study area, and a large proportion of this dense coverage is within Biscayne National Park. Red mangroves predominate in these locations and possess the robust 


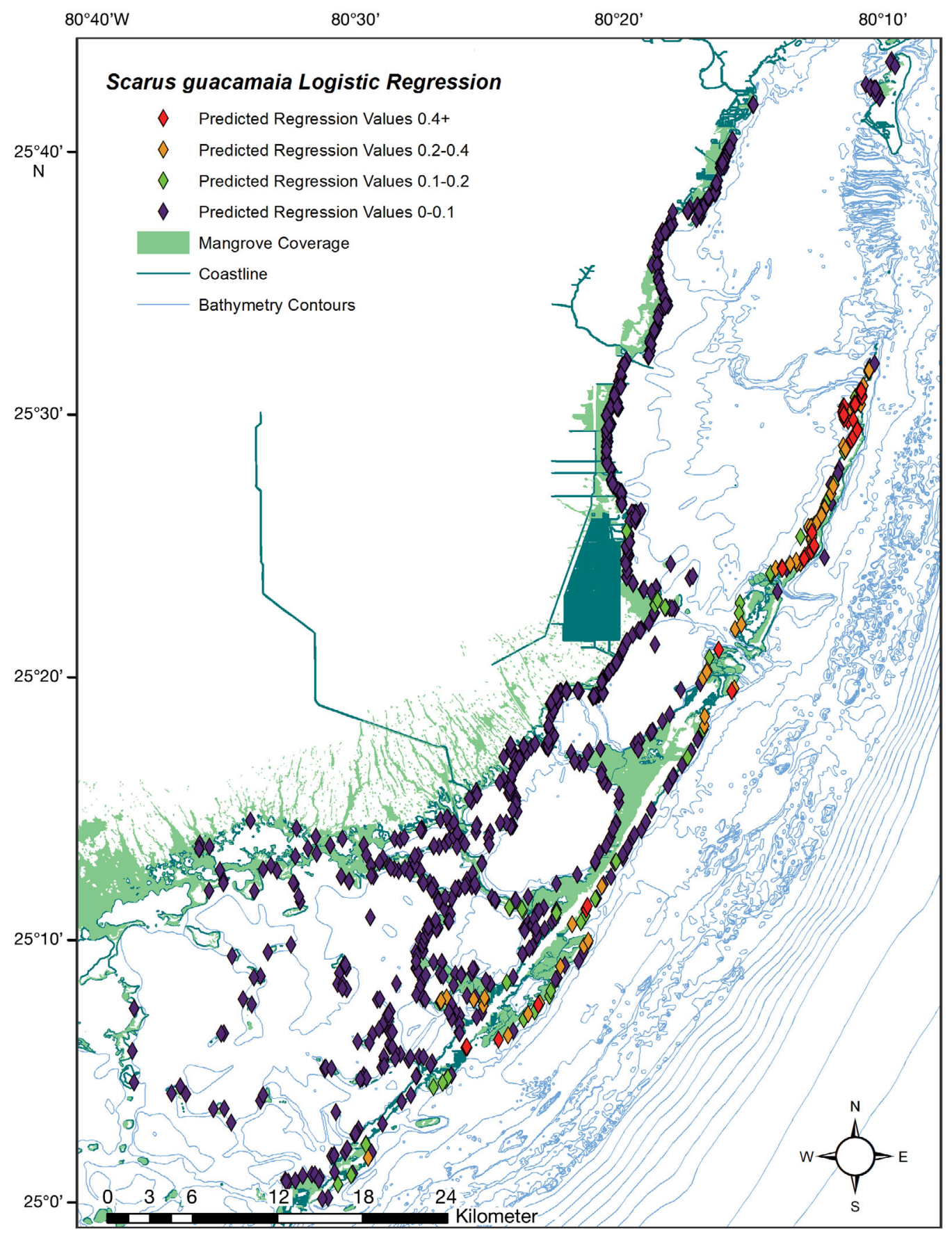

Fig. 4. Scarus guacamaia. Map of MVS study sites (1998-2009) color-coded for predicted logistic regression values from a model of water depth, distance from offshore channel openings, temperature variation, and salinity variation. Low values for regression model suggest sites where rainbow parrotfish are more likely to be absent, while high values suggest sites where rainbow parrotfish are likely to be present

emergent prop roots that provide shelter and substrate for epiphytic macroalgae. Moderate predicted regression values were found on windward sites outside of Biscayne National Park and in Card Sound and Upper Florida Bay. The seaward edges of Barnes and Blackwater Sound also possess high fringing mangrove coverage as well as riverine and basin mangrove communities (Ishman 1997). These sites have high salinity values around seawater strength and short distances from the openings to offshore 
channels. In addition, the average depth combined with hardbottom substrate creates refugia and substrate for Halimeda spp. and Caulerpa spp. macroalgae.

The lowest predicted values were found on the mainland shorelines. These areas experience lower and more variable salinity regimes due to short-term salinity fluctuations and the limited tidal flushing of the western margins of Biscayne Bay (Wang et al. 2003). These salinity regimes probably have a direct effect on rainbow parrotfish in terms of adversely affecting individual osmoregulatory capacities. In addition, there is reduced mangrove coverage in these areas and a frequently present mud embankment, which acts to separate marine habitats from the mainland and impede freshwater runoff (Ishman 1997).

Logistic regression has many limitations for habitat modeling (see Pearce \& Ferrier 2000). The most notable is that incomplete detectability may lead to false negatives, which could indicate that an animal does not occur in a habitat when it was actually just missed. Another limitation is the influence of nonlinearities and interactions among the variables, all of which cannot be accounted for in this type of modeling (see De'ath 2007). A more theoretically satisfying treatment of similar data is to model occupancy (the probability that an animal occupies the habitat) as a separate process from detectability (the probability that an occupant of the habitat is observed) (MacKenzie et al. 2003). However, this approach requires repeated sampling at the same sites, which is not often part of long-term monitoring programs (and was not part of the MVS). Nevertheless, incomplete detection is unlikely to bias signals from the significant factors in this analysis, provided that detection probability does not strongly correlate with any of the model factors. Further, the additional false negatives in locations where Scarus guacamaia are likely to be occupants introduce unexplained variability rather than bias.

Additional sources of unexplained variability in logistic regression are unmeasured variables. For the current model, only $40 \%$ of the deviance is explained, indicating that there is substantial unexplained variability. Nonetheless, the model had reasonable performance (i.e. $94 \%$ accuracy) in accurately predicting the presence and absence of Scarus guacamaia using independent data from 2008 and 2009. In any habitat model, unmeasured variables could account for much of the unexplained variance. One such unquantified variable is local bottom substrate. Frias-Torres (2006) noted that bottom substrate complexity was a deter- minate factor for the presence of juvenile goliath grouper Epinephelus itajara. For rainbow parrotfish, different bottom substrate types may also have important roles in supporting macroalgae. Future habitat modeling work for S. guacamaia should thus consider measurements that better allow the characterization of local bottom substrate type.

The findings of this logistic regression model have important conservation implications for rainbow parrotfish. Though parrotfishes are a major component of reef and subsistence fisheries (Hughes et al. 2007) in the greater Caribbean, they are protected from fishing in South Florida, and their main threat is a reduction in habitat. The $80 \%$ reduction in mangrove coverage in the South Florida ecosystem has also resulted in a substantial loss of potential habitat for this and many other species (Snedaker \& Biber 1996). Furthermore, much of what habitat remains experiences unnatural (and apparently unsuitable for Scarus guacamaia) salinity variability due to anthropogenic water management practices. Changes to current water management regimes in South Florida may enhance the habitat quality of Biscayne Bay through the creation of a less-pulsed salinity regime that more resembles a natural estuary.

The findings of this study also could be extrapolated for use outside of Florida and the sampling area. Regions in the Caribbean Sea such as Venezuela, Bonaire, and Curaçao support rainbow parrotfish, and similar environmental variables could be targeted with these methods of habitat modeling. In addition, other parrotfish species that similarly utilize mangrove habitats and have similar life histories, such as stoplight parrotfish Sparisoma viride and midnight parrotfish Scarus coelestinus, could be studied in greater detail with this type of habitat modeling. The results may also be applicable in the Indo-Pacific region with species such as the humphead wrasse Cheilinus undulatus (Dorenbosch et al. 2006) and in areas such as Mo'orea, French Polynesia, where herbivory responses, especially those by parrotfish, have already been shown to confer greater resilience to coral reefs after disturbances (Adam et al. 2011).

Scarus guacamaia has several important roles in the dynamics of tropical coral reefs, most directly by grazing on macroalgae that competes spatially with the threatened corals Acropora palmata and A. cervicornis. Due to this role, enhancement or maintenance of their remaining juvenile habitats may result in benefits to nearby coral reefs. Rainbow parrotfish, through an ontogenetic connectivity between mangrove habitats and coral reefs, may serve as a critical 
link between terrestrial land and water management practices in South Florida and the protection and enhancement of the delicate Florida coral reef system and threatened acroporid corals.

Acknowledgements. We thank B. Teare, D. L. Jones, B. K. Walker, and J. A. Bohnsack for their technical assistance. Financial support for the mangrove-fish surveys was provided by RECOVER (US Army Corps of Engineers and South Florida Water Management District) and the Southeast Fisheries Science Center, National Marine Fisheries Service, NOAA.

\section{LITERATURE CITED}

National Marine Fisheries Service (2006) Endangered and threatened species: final listing determinations for elkhorn coral and staghorn coral, final rule. Fed Regist 71:26852-26872

National Marine Fisheries Service (2011) Fisheries of the Caribbean, Gulf of Mexico, and South Atlantic; amendments to the queen conch and reef fish fishery management plans of Puerto Rico and the U.S. Virgin Islands, proposed rule. Fed Regist 76:66675-66681

Adam TC, Schmitt RJ, Holbrook SJ, Brooks AJ, Edmunds PJ, Carpenter RC, Bernardi G (2011) Herbivory, connectivity, and ecosystem resilience: response of a coral reef to a large-scale perturbation. PLoS ONE 6:e23717

Arthur JF, Ball MD (1979) Factors influencing the entrapment of suspended material in the San Francisco BayDelta Estuary. In: Conomos T (ed) San Francisco Bay: the urbanized estuary. California Academy of Sciences, San Francisco, CA, p 143-174

Bellwood DR, Hughes TP, Folke C, Nyström M (2004) Confronting the coral reef crisis. Nature 429:827-833

Bi H, Ruppel RE, Peterson WT (2007) Modeling the pelagic habitat of salmon off the Pacific Northwest (USA) coast using logistic regression. Mar Ecol Prog Ser 336:249-265

Bohnsack JA, Bannerot SP (1986) A stationary visual census technique for quantitatively assessing community structure of coral reef fishes. NOAA Tech Rep 41:15, National Marine Fisheries Service, Miami, FL

Bortone SA, Van Tassell T, Brito A, Falcon JM, Bundrick CM (1992) Visual census as a means to estimate standing biomass, length, and growth in fishes. In: Diving for science. AAUS, Costa Mesa, CA, p 13-21

Burnham KP, Anderson DR (2002) Model selection and multimodel inference: a practical information-theoretic approach, 2nd edn. Springer-Verlag, New York, NY

> Chesney EJ, Baltz DM, Thomas RG (2000) Louisiana estuarine and coastal fisheries and habitats: perspectives from a fish's eye view. Ecol Appl 10:350-366

> De Almeida e Silva T, Neumann-Leitão S, Schwamborn R, de Oliveira Gusmão LM, do Nascimento-Vieira DA (2003) Diel and seasonal changes in the macrozooplankton community of a tropical estuary in Northeastern Brazil. Rev Bras Zool 20:439-446

> De'ath G (2007) Boosted trees for ecological modeling and prediction. Ecology (USA) 88:243-251

> Dorenbosch M, Grol MGG, Nagelkerken I, van der Velde G (2006) Seagrass beds and mangroves as potential nurseries for the threatened Indo-Pacific humphead wrasse,
Cheilinus undulatus and Caribbean rainbow parrotfish, Scarus guacamaia. Biol Conserv 129:277-282

> Dorenbosch M, Verberk WCEP, Nagelkerken I, van der Velde G (2007) Influence of habitat configuration on connectivity between fish assemblages of Caribbean seagrass beds, mangroves and coral reefs. Mar Ecol Prog Ser 334:103-116

Ferreira CE, Ferreira B, Rocha LA, Gaspar AL, Feitosa C, Choat JH (2008) Scarus guacamaia. IUCN 2010, IUCN Red List of Threatened Species, Version 2010.4. Accessed 19 Feb 2011. www.iucnredlist.org

- Fransen BR, Duke SD, McWethy LG, Walter JK, Bilby RE (2006) A logistic regression model for predicting the upstream extent of fish occurrence based on geographical information systems data. North Am J Fish Manage 26:960-975

> Freckleton RP, Noble D, Webb TJ (2006) Distributions of habitat suitability and the abundance-occupancy relationship. Am Nat 167:260-275

- Freeman EA, Moisen GG (2008) A comparison of the performance of threshold criteria for binary classification in terms of predicted prevalence and kappa. Ecol Model 217:48-58

Frias-Torres S (2006) Habitat use of juvenile goliath grouper Epinephelus itajara in the Florida Keys, USA. Endang Species Res 2:1-6

> Häder DP, Porst M, Herrmann H, Schäfer J, Santas R (1997) Photosynthesis of the Mediterranean green alga Caulerpa prolifera measured in the field under solar irradiation. Photochem Photobiol 37:66-73

Hughes TP, Bellwood DR, Folke CS, McCook LJ, Pandolfi JM (2007) No-take areas, herbivory and coral reef resilience. Trends Ecol Evol 22:1-3

Ishman SE (1997) Ecosystem history of South Florida: Biscayne Bay sediment core descriptions. U.S. Geological Survey, Reston, VA

MacKenzie DI, Nichols JD, Hines JE, Knutson MG, Franklin AD (2003) Estimating site occupancy, colonization and local extinction when a species is detected imperfectly. Ecology (USA) 84:2200-2207

McClanahan T, Polunin N, Done T (2002) Ecological states and the resilience of coral reefs. Conserv Ecol 6:18 Available at www.consecol.org/vol6/iss2/art18/

Mumby PJ (2006) Connectivity of reef fish between mangroves and coral reefs: algorithms for the design of marine reserves at seascape scales. Biol Conserv 128:215-222

Mumby PJ, Hastings A (2008) The impact of ecosystem connectivity on coral reef resilience. J Appl Ecol 45:854-862

Mumby PJ, Edwards AJ, Arias-Gonzalez JE, Lindeman KC and others (2004) Mangroves enhance the biomass of coral reef fish communities in the Caribbean. Nature 427:533-536

Nagelkerken I (2007) Are non-estuarine mangroves connected to coral reefs through fish migration? Bull Mar Sci 80:595-607

Nagelkerken I, van der Velde G (2002) Do non-estuarine mangroves harbour higher densities of juvenile fish than adjacent shallow-water and coral reef habitats in Curaçao (Netherlands Antilles)? Mar Ecol Prog Ser 245:191-204

> Nagelkerken I, Dorenbosch M, Verberk WCEP, Cocheret de la Morinière E, van der Velde G (2000) Importance of shallow-water biotopes of a Caribbean bay for juvenile coral reef fishes: patterns in biotope association, community structure and spatial distribution. Mar Ecol Prog Ser 202:175-192 
Olmsted I, Loope LL (1984) Plant communities of Everglades National Park. In: Gleason PJ (ed) Environments of South Florida, past and present II. Miami Geological Society, Coral Gables, FL, p 167-184

Paddack MJ, Sponaugle S, Cowen RK (2009) Small-scale demographic variation in the stoplight parrotfish Sparisoma viride. J Fish Biol 75:2509-2526

Pearce J, Ferrier S (2000) Evaluating the predictive performance of habitat models developed using logistic regression. Ecol Model 133:225-245

Rummer JL, Fangue NA, Jordan HL, Tiffany BN and others (2009) Physiological tolerance to hyperthermia and hypoxia and effects on species richness and distribution of rockpool fishes of Loggerhead Key, Dry Tortugas National Park. J Exp Mar Biol Ecol 371:155-162

Sampson DB, Al-Jufaily SM (1999) Geographic variation in the maturity and growth schedules of English sole along the U.S. west coast. J Fish Biol 54:1-17

Serafy JE, Lindeman KC, Hopkins TE, Ault JS (1997) Effects of freshwater canal discharge on fish assemblages in a subtropical bay: field and laboratory observations. Mar Ecol Prog Ser 160:161-172

Serafy JE, Faunce CH, Lorenz JJ (2003) Mangrove shoreline fishes of Biscayne Bay, Florida. Bull Mar Sci 72:161-180

Editorial responsibility: Sean Connell,

Adelaide, Australia
Serafy JE, Valle M, Faunce CH, Luo J (2007) Speciesspecific patterns of fish size and abundance along a subtropical mangrove shoreline: application of the delta approach. Bull Mar Sci 80:609-624

Serrano X, Grosell M, Serafy JE (2010) Salinity selection and preference of the grey snapper Lutjanus griseus: field and laboratory observations. J Fish Biol 76:1592-1608

Smith CL (1997) National Audubon Society field guide to tropical marine fishes of the Caribbean, the Gulf of Mexico, Florida, the Bahamas, and Bermuda. Alfred A. Knopf, New York, NY

Smith TB (2008) Temperature effects on herbivory for an Indo-Pacific parrotfish in Panamá: implications for coralalgal competition. Coral Reefs 27:397-405

Snedaker SC, Biber PD (1996) Restoration of mangroves in the United States of America: a case study in Florida. In: Field CD (ed) Restoration of mangrove ecosystems. ISME, Okinawa, p 170-188

Wang JD, Luo J, Ault JS (2003) Flows, salinity and some implications for larval transport in South Biscayne Bay, Florida. Bull Mar Sci 72:695-723

Winn HE, Bardach JE (1960) Some aspects of the comparative biology of parrotfishes at Bermuda. Zoologica 45: 29-34

Submitted: August 24, 2011; Accepted: February 13, 2012 Proofs received from author(s): April 21, 2012 